\title{
Simultaneous Polymerization and Formation of Poly(propargyl alcohol) Films by a Novel Palladium Catalyst
}

\author{
Mujie Yang, Hongmei Sun, and Weiguo CHEN* \\ Department of Polymer Science and Engineering, Zhejiang University, \\ Hangzhou 310027, China \\ * Department of Chemistry, Hangzhou University, Hangzhou 310013, China
}

(Received March 27, 1995)

\begin{abstract}
Simultaneous polymerization and formation of poly(propargyl alcohol) (POHP) films by $\left[\mathrm{Pd}\left(\mathrm{C} \equiv \mathrm{CCH}_{2} \mathrm{OH}\right)_{2}\left(\mathrm{PPh}_{3}\right)_{2}\right](\mathrm{Pd}-\mathrm{C})$ catalyst in $\mathrm{CH}_{2} \mathrm{Cl}_{2}-\mathrm{CCl}_{4}$ mixed solvent system have been investigated. Some features and kinetic behavior for the OHP polymerization are described and discussed. The overall polymerization activation energy was found to be $76.4 \mathrm{k} \mathrm{J} \mathrm{mol}^{-1}$ and the rate equation can be expressed as $R_{\mathrm{p}}=k_{\mathrm{p}}[\mathrm{OHP}][\mathrm{Pd}-\mathrm{C}]$, where $k_{\mathrm{p}}=1.32 \times 10^{-3} \mathrm{~L} \mathrm{~mol}^{-1} \mathrm{~s}^{-1}$ $\left(58^{\circ} \mathrm{C}\right)$. The POHP polymer obtained is a black sheeny film stable in air and chlorinated by $\mathrm{CH}_{2} \mathrm{Cl}_{2}-\mathrm{CCl}_{4}$ mixed solvent. Its conducting properties were investigated.

KEY WORDS Propargyl Alcohol / Bis(triphenylphosphine)-Bis(2-propinyl1-ol)palladium Catalyst / Polymerization / Poly(propargyl alcohol) Film /
\end{abstract}

Since Shirakawa et al. ${ }^{1}$ succeeded in synthesizing a uniform and free standing film of polyacetylene by a direct method in 1974 , there have been many studies on polyacetylene. ${ }^{2}$ Particularly, doped polyacetylene shows the metallic conductivity, which has received a great deal of attention in the past years. However, polyacetylene is unstable in air and insoluble in the usual organic solvents. Thus, though the electrical conductivity is somewhat low, the synthesis and properties of substituted polyacetylene have been intensively investigated. ${ }^{3}$ Poly(propargyl alcohol) (POHP) is one of them. But, there was no much satisfaction with the results of the synthesis of POHP in the past 30 years. ${ }^{4-5}$ Recently, we reported that a bis(triphenylphosphine)-bisacetylide palladium complex $\mathrm{Pd}\left(\mathrm{C} \equiv \mathrm{CCH}_{2} \mathrm{OH}\right)_{2}\left(\mathrm{PPh}_{3}\right)_{2}(\mathrm{Pd}-\mathrm{C})$ is a novel effective catalyst for the OHP homogeneous polymerization in $\mathrm{CHCl}_{3}-\mathrm{CH}_{3} \mathrm{OH}$ mixed solvent system at $60^{\circ} \mathrm{C} .{ }^{7}$ In the present paper we report further research results on simultaneous polymerization and formation of POHP film with $\mathrm{Pd}-\mathrm{C}$ catalyst in $\mathrm{CH}_{2} \mathrm{Cl}_{2}-\mathrm{CCl}_{4}$ mixed solvent system at about $60^{\circ} \mathrm{C}$, which in turn is a development based upon our previous work on the acetylene, phenylacetylene polymerization. $^{8,9}$

\section{EXPERIMENTAL}

\section{Materials}

Propargyl alcohol (OHP), 2-propinyl-1-ol, was distilled under nitrogen at reduced pressure. All the reagents (palladium chloride, cuprous iodide, diethylamine, triphenylphosphine, and ferric chloride anhydrous, etc.) were analytical or chemical grade. trans-Bis(triphenylphosphine) dichloropalladium $\mathrm{Pd}$ $\mathrm{Cl}_{2}\left(\mathrm{PPh}_{3}\right)_{2}$ was prepared by a classical method. A typical reaction procedure is given here: $0.1400 \mathrm{~g}$ of $\mathrm{PdCl}_{2}, 0.0944 \mathrm{~g}$ of $\mathrm{NaCl}$ dissolved in small amount of water, and $300 \mathrm{ml}$ of ethanol were added to a $1000 \mathrm{ml}$ reaction flask. The mixture was maintained under stirring at $50^{\circ} \mathrm{C}$ for about $4 \mathrm{~h}$, then filtered. An ethanol solution containing $0.4142 \mathrm{~g}$ of $\mathrm{PPh}_{3}$ was 
added to the filtrate. The reaction mixture was stirred at $50^{\circ} \mathrm{C}$ for about $10 \mathrm{~min}$. The yellow precipitate formed was separated by filtration, washed with warm ethanol, then dried in vacuo, yield about $85 \%$. The UV spectrum in $\mathrm{CHCl}_{3}$ of $\mathrm{PdCl}_{2}\left(\mathrm{PPh}_{3}\right)_{2}$ exhibits a maximum at $216.8 \mathrm{~nm}$. Anal. Calcd for $\mathrm{Pd}\left(\mathrm{Cl}_{2} \mathrm{P}_{2} \mathrm{C}_{36} \mathrm{H}_{30}\right)$ : $\mathrm{C}, 61.60 \%$; H, $4.28 \%$, Found: C, $61.48 \% ; \mathrm{H}$, $4.27 \%$.

The complex $\left[\mathrm{Pd}\left(\mathrm{C} \equiv \mathrm{CH}_{2} \mathrm{OH}\right)_{2}\left(\mathrm{PPh}_{3}\right)_{2}\right]$ $(\mathrm{Pd}-\mathrm{C})$ was prepared as previously reported. ${ }^{7}$

\section{Polymerization}

All procedures for polymerization were carried out under purified nitrogen atmosphere. A typical polymerization procedure is as follows: into a $30 \mathrm{ml}$ well-dried ampoule, $\mathrm{Pd}-\mathrm{C}$ as the catalyst, $\mathrm{CH}_{2} \mathrm{Cl}_{2}$ and $\mathrm{CCl}_{4}$ were added in turn, shaked and/or heated $\left(<60^{\circ} \mathrm{C}\right)$ to obtain a homogeneous solution, and then propargyl alcohol (OHP) was injected. After the mixture stood at $58^{\circ} \mathrm{C}$ for a definite reaction time, a black sheeny polymer (POHP) film was formed, the filtered, washed with hexane, chloroform-ethanol mixed solvent, ethanol in this order, and dried at room temperature under vacuum for about $8 \mathrm{~h}$. The polymer yield was calculated by gravimetry.

\section{Doping}

POHP was doped by dipping the film into a solution of $\mathrm{I}_{2}$ in hexane, or of $\mathrm{I}_{2}$ in dichloromethane, or of $\mathrm{FeCl}_{3}$ in nitromethane, or of $\mathrm{H}_{2} \mathrm{SO}_{4}$ in tetrahydrofuran. After a definite time, the solvent was eliminated under vacuum. The residue was repeatedly washed with solvents used in the doping procedure and then dried in vacuum at room temperature. The doping levels were determined by the weight uptake method.

\section{Measurements}

Infrared (IR) spectra were recorded on a Nicolet 5-DX FTIR with a $\mathrm{KBr}$ pellet. The elemental analyses were carried out by a Carloerba Model 1106 elemental analyzer.
Electron spin resonance (ESR) measurements were taken on a JES-FEIXG ESR spectrometer. Ultraviolet (UV) spectra were recorded on a Shimadzu UV 240 spectrometer. Electrical resistivities were measured by the highresistance meter (mod. ZC36), and carried out at room temperature on the pellets compressed at $600 \mathrm{~kg} \mathrm{~cm}^{-2}$. The chlorinity of POHP polymer was detected by oxygen flask method.

\section{RESULTS AND DISCUSSION}

Features of OHP Polymerization with $\mathrm{Pd}(\mathrm{C} \equiv$ $\left.\mathrm{CCH}_{2} \mathrm{OH}\right)_{2}\left(\mathrm{PPh}_{3}\right)_{2}$ Catalyst

The $\mathrm{Pd}\left(\mathrm{C} \equiv\left(\mathrm{CH}_{2} \mathrm{OH}\right)_{2}\left(\mathrm{PPh}_{3}\right)_{2}(\mathrm{Pd}-\mathrm{C})\right.$ is a novel catalyst for the polymerization of propargyl alcohol (OHP). ${ }^{7}$ Solvent system is a key factor for simultaneous polymerization and formation of POHP films and greatly influences the polymerization activity. In general, simultaneous polymerization and formation of polymer films easily carry out in a mixed solvent system consisted of solvent and nonsolvent of the polymer. It was found that the OHP could polymerize with $\mathrm{Pd}-\mathrm{C}$ catalyst in the solvent systems that follow: $\mathrm{CCl}_{4}, \mathrm{CHCl}_{3}$ $\mathrm{CH}_{3} \mathrm{OH}, \mathrm{CHCl}_{3}-\mathrm{CCl}_{4}, \mathrm{CH}_{2} \mathrm{Cl}_{2}-\mathrm{CCl}_{4}$, $\mathrm{C}_{2} \mathrm{H}_{5} \mathrm{OH}-\mathrm{CCl}_{4}$, and toluene- $\mathrm{CCl}_{4}$. Of all the solvent systems, however, $\mathrm{CH}_{2} \mathrm{Cl}_{2}-\mathrm{CCl}_{4}$ mixed solvent is a favorable one for simultaneous polymerization and formation of POHP film, while the conversion for the OHP polymerization reached $90 \%$ under the tested conditions. The effect of $\mathrm{CCl}_{4}$ concentration $\left[\mathrm{CCl}_{4}\right]$ on the conversion of POHP films is shown in Figure 1. With increasing the $\mathrm{CCl}_{4}$ concentration up to $5 \mathrm{~mol} \mathrm{~L}^{-1}$, the polymerization conversion increases. In fact, for obtaining high quality of POHP films, the optimum $\mathrm{CCl}_{4}$ concentration is $3.10 \mathrm{~mol} \mathrm{~L}^{-1}$, that is, the volume ratio of $\mathrm{CH}_{2} \mathrm{Cl}_{2} / \mathrm{CCl}_{4}$ is $1\left(V_{\mathrm{C}} / V_{\mathrm{T}}=1\right)$, both above and below this concentration, the POHP films obtained were not good.

The $\mathrm{Pd}-\mathrm{C}$ complex is also an effective catalyst for $\mathrm{OHP}$ polymerization in $\mathrm{CH}_{2} \mathrm{Cl}_{2}$ 


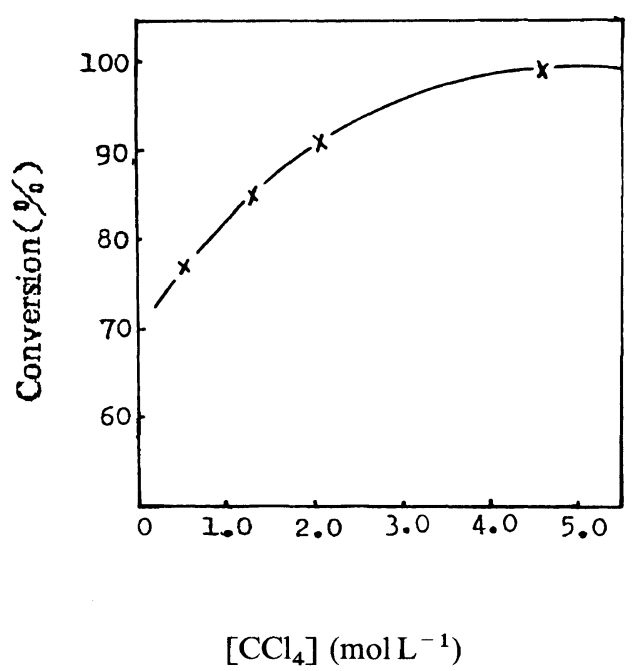

Figure 1. Effect of $\mathrm{CCl}_{4}$ concentration $\left[\mathrm{CCl}_{4}\right]$. Conditions: $\mathrm{CH}_{2} \mathrm{Cl}_{2}-\mathrm{CCl}_{4}$ solvent system; $[\mathrm{Pd}-\mathrm{C}]=3.0 \times 10^{-2}$ $\mathrm{mol} \mathrm{L}{ }^{-1} ;[\mathrm{OHP}]=6.8 \mathrm{~mol} \mathrm{~L}^{-1} ; \mathrm{N}_{2} ; 58^{\circ} \mathrm{C}$ and $24 \mathrm{~h}$.

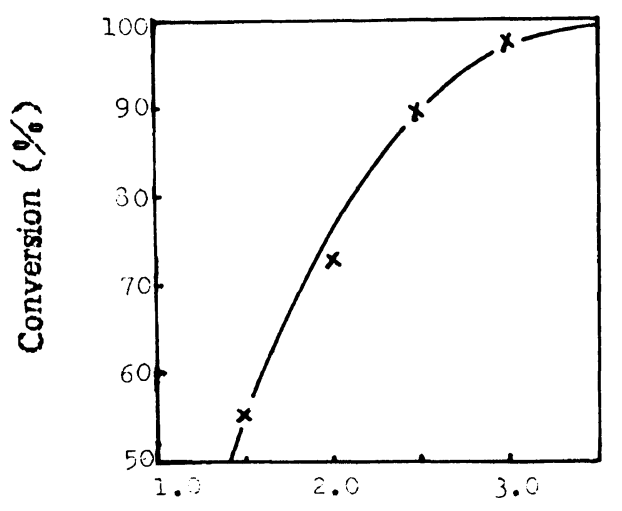

$[\mathrm{Pd}-\mathrm{C}] \times 10^{2}\left(\mathrm{~mol} \mathrm{~L}^{-1}\right)$

Figure 2. Effect of catalyst concentration [Pd-C]. Conditions: $\mathrm{CH}_{2} \mathrm{Cl}_{2} / \mathrm{CCl}_{4}=1$ (volume ratio), others are the same as in Figure 1.

$\mathrm{CCl}_{4}$ mixed solvent system at $58^{\circ} \mathrm{C}$. The effect of catalyst $\mathrm{Pd}-\mathrm{C}$ and monomer OHP concentration, and polymerization temperature on the OHP polymerization are illustrated in Figures 2, 3, and 4. It is seen that the conversion for the OHP polymerization increases rapidly with increasing catalyst concentration and polymerization temperature, and de-

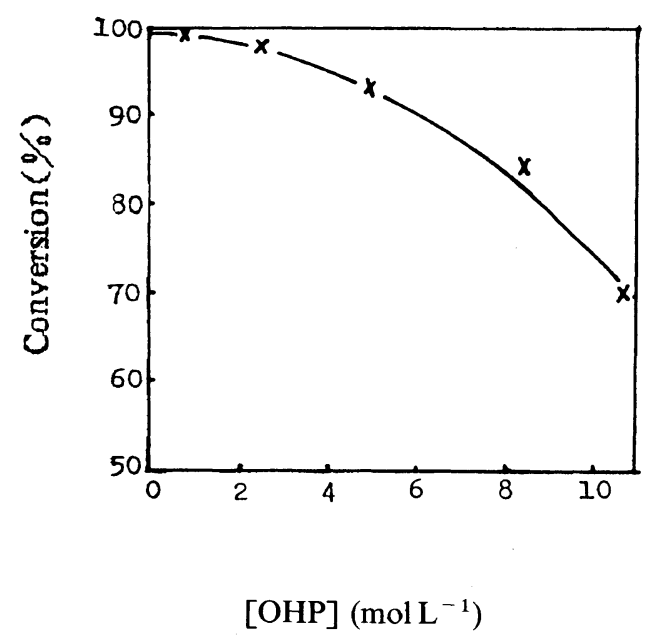

Figure 3. Effect of monomer concentration [OHP]. Conditions: $\mathrm{CH}_{2} \mathrm{Cl}_{2} / \mathrm{CCl}_{4}=1$ (volume ratio), others are the same as in Figure 1.

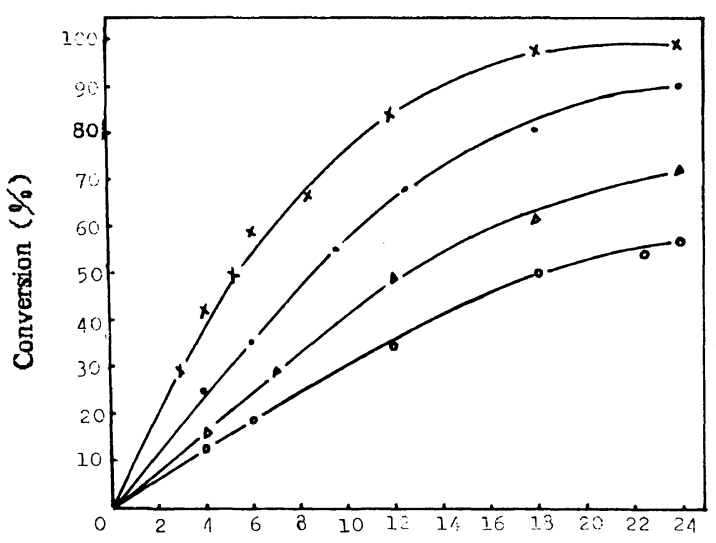

Figure 4. Time-conversion curves for the OHP polymerization at different temperature, $T,{ }^{\circ} \mathrm{C}$ : $(O) 45 ;(\triangle)$ 50; (○) 55; ( $\times$ ) 58. Conditions: $\mathrm{CH}_{2} \mathrm{Cl}_{2} / \mathrm{CCl}_{4}=1$ (volume ratio), others are the same as in Figure 1.

creases with increasing monomer concentration. For combination of high conversion and obtaining better POHP films, the optimum catalyst and monomer concentration, and polymerization temperature are considered $3.0 \times 10^{-2} \mathrm{~mol} \mathrm{~L}^{-1}$ of $\mathrm{Pd}-\mathrm{C}, 6.8 \mathrm{~mol} \mathrm{~L}^{-1}$ of $\mathrm{OHP}$, and $58^{\circ} \mathrm{C}$. respectively, under the tested conditions $\left(V_{\mathrm{C}} / V_{\mathrm{T}}=1\right.$, after $12 \mathrm{~h}$ polymerization). 
Kinetic Behavior of Polymerization

The kinetic behavior of simultaneously polymerizing and forming of POHP films with the $\mathrm{Pd}-\mathrm{C}$ catalyst in $\mathrm{CH}_{2} \mathrm{Cl}_{2}-\mathrm{CCl}_{4}$ mixed solvent system at $58^{\circ} \mathrm{C}$ has been studied. It is seen from Figure 4 that the conversion increases linearly up to $6 \mathrm{~h}$, and subsequently levels off. The apparent polymerization rate $\left(R_{\mathrm{p}}\right)$ at different catalyst concentrations [Pd$C]$ was calculated from the conversion measured in the initial stage at constant monomer concentration $[\mathrm{OHP}]=6.8 \mathrm{~mol} \mathrm{~L}^{-1}$. Figure 5 is the plot of $\log R_{\mathrm{p}} v s . \log [\mathrm{Pd}-\mathrm{C}]$ and indicates that $\log R_{\mathrm{p}}$ is in a linear relationship with $\log [\mathrm{Pd}-\mathrm{C}]$ having a slope of approaching 1 , i.e., the polymerization reaction is of first order with respect to catalyst concentration [Pd-C]. Figure 6 shows some polymrrization times versus $-\ln (1-c)$ curves at different $[\mathrm{Pd}-\mathrm{C}]$. From Figure 6 it is clear that the polymerization reaction is of first order with respect to monomer concentration [OHP] under the catalyst concentration tested. Thus the polymerization rate equation can be written as:

$$
R_{\mathrm{p}}=k_{\mathrm{p}}[\mathrm{OHP}][\mathrm{Pd}-\mathrm{C}]
$$

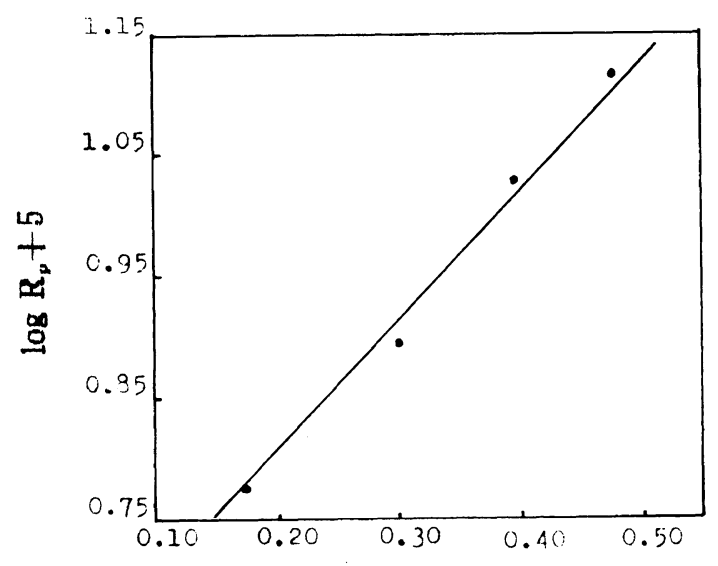

$\log [\mathrm{Pd}-\mathrm{C}]+2$

Figure 5. Plot of $\log R_{\mathrm{p}}$ vs. $\log [\mathrm{Pd}-\mathrm{C}]$. Conditions: $\mathrm{CH}_{2} \mathrm{Cl}_{2} / \mathrm{CCl}_{4}=1$ (volume ratio), $[\mathrm{OHP}]=6.8 \mathrm{~mol} \mathrm{~L}^{-1}$, $\mathrm{N}_{2}$, and $58^{\circ} \mathrm{C}$. where $k_{\mathrm{p}}$ is the apparent polymerization rate constant, equal to $1.32 \times 10^{-3} \mathrm{~L} \mathrm{~mol}^{-1} \mathrm{~s}^{-1}$ $\left(58^{\circ} \mathrm{C}\right)$.

Figure 7 shows the influence of polymerization temperature and indicates an Arrheniustype dependence. Thus, the overall activation energy of OHP polymerization with $\mathrm{Pd}-\mathrm{C}$ catalyst was found to be $76.4 \mathrm{k} \mathrm{J} \mathrm{mol}^{-1}$.

Besides, it was observed that the OHP polymerization was not suppressed by in-

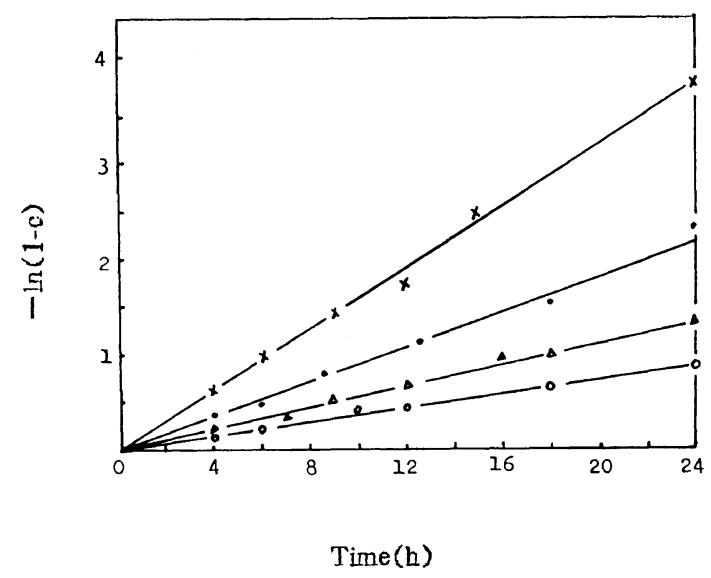

Figure 6. Reaction time $v s$. $-\ln (1-c)$ curves for the OHP polymerization at different catalyst concentration. $[\mathrm{Pd}-\mathrm{C}], \mathrm{mol} \mathrm{L}^{-1}:(\times) 3.0 \times 10^{-2}$; (O) $2.5 \times 10^{-2} ;(\triangle)$ $2.0 \times 10^{-2}$; (O) $1.5 \times 10^{-2}$. Conditions are the same as in Figure 5 .

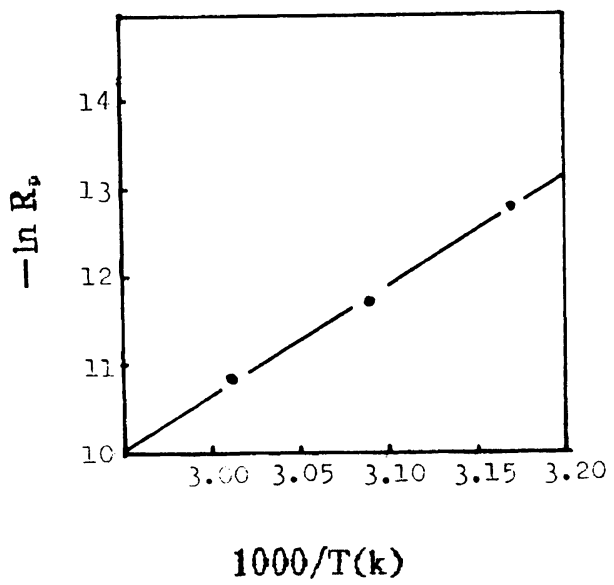

Figure 7. Arrhenius plot of the rate of polymerization $\left(R_{\mathrm{p}}\right)$ vs. temperature. Conditions: $\mathrm{CH}_{2} \mathrm{Cl}_{2} / \mathrm{CCl}_{4}=1$ (volume ratio); $[\mathrm{Pd}-\mathrm{C}]=3.0 \times 10^{-2} \mathrm{~mol} \mathrm{~L}^{-1} ;[\mathrm{OHP}]=6.8$ $\mathrm{molL}^{-1}, \mathrm{~N}_{2}$. 
corporation of hydroquinone in the medium, and was accelerated by adding a solution of $\mathrm{FeCl}_{3}$ in $N, N$-dimethylformamide (DMF) to the polymerization system. Moreover, no free radical signal was detected while dynamic tracing the OHP polymerization with ESR. Combining the above experimental facts, it can be seen that the OHP polymerization with $\mathrm{Pd}-\mathrm{C}$ catalyst in $\mathrm{CH}_{2} \mathrm{Cl}_{2}-\mathrm{CCl}_{4}$ mixed solvent system at $58^{\circ} \mathrm{C}$ is probably not free radical polymerization. Precise investigation on the polymerization mechanism will be continued.

\section{Characterization and Doping of Polymer}

Poly(propargyl alcohol)(POHP) so prepared by $\mathrm{Pd}-\mathrm{C}$ catalyst in $\mathrm{CH}_{2} \mathrm{Cl}_{2}-\mathrm{CCl}_{4}$ mixed solvent system at $58^{\circ} \mathrm{C}$ is a black sheeny film. It is insoluble in most organic solvents, but soluble partially in DMF. The infrared spectra of POHP films obtained (Figure 8) show the characteristic absorption peak of conjugated $\mathrm{C}=\mathrm{C}$ bonds $\left(1655 \mathrm{~cm}^{-1}\right)$, of $\mathrm{CH}_{2} \mathrm{OH}$ groups $\left(1025 \mathrm{~cm}^{-1}\right)$, while the monomeric triple bond $(\mathrm{C} \equiv \mathrm{C})$ peak at $2120 \mathrm{~cm}^{-1}$ is missing. The UV analysis of POHP film revealed an absorption maximum (in DMF) at $356.5 \mathrm{~nm}$, which indicated forming a $\pi$-conjugated chain.

The POHP polymer is stable in air. No noticeable weight uptake and no remarkable change in IR spectra (Figure 8) were examined with storage time.

Preliminary conductivity measurements of the POHP films doped with $\mathrm{I}_{2}$ /hexane, $\mathrm{I}_{2} /$ dichloromethane, $\mathrm{FeCl}_{3} /$ nitromethane, and $\mathrm{H}_{2} \mathrm{SO}_{4}$ /tetrahydrofuran gave values of about $5.9 \times 10^{-9}, 2.1 \times 10^{-9}$, and $2.1 \times 10^{-8} \mathrm{~s} \mathrm{~cm}^{-1}$, respectively, which increased by $3-4$ orders of magnitude as compared to the undoped POHP film.

It is worth noting that the POHP films obtained were chlorinated by $\mathrm{CH}_{2} \mathrm{Cl}_{2}-\mathrm{CCl}_{4}$ mixed solent in the polymerization process, which is confirmed by the IR spectra and $\mathrm{Cl}$-content measurements of the POHP films. Characteristic absorptions of $\mathrm{C}-\mathrm{Cl}$ bond (750 and $790 \mathrm{~cm}^{-1}$ ) indicating a chlorine containing

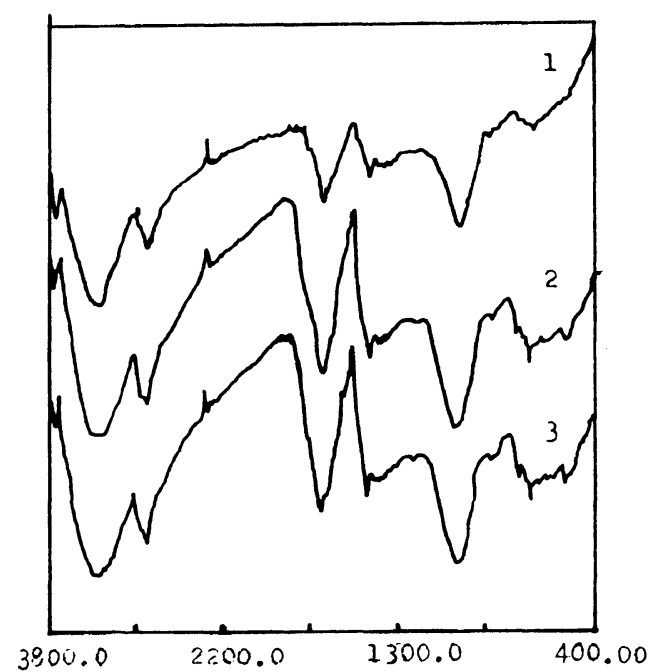

\section{WAYENUMBERS $\left(\mathrm{CM}^{-1}\right)$}

Figure 8. Infrared spectra of POHP films in different atmosphere at room temperature for 7 days: (1) in $\mathrm{N}_{2}$; (2) in air; (3) in vacuum.

of POHP films were observed in the IR spectra (Figure 8). The $\mathrm{Cl}$-content analysis revealed that the $\mathrm{Cl}$-content of the POHP film obtained under the experimental conditions is about $13 \mathrm{wt} \%$, and increases with increasing mole ratio of $\mathrm{CH}_{2} \mathrm{Cl}_{2}-\mathrm{CCl}_{4}$ mixed solvent to monomer OHP. The above results indicated that, perhaps, this POHP polymer could be used as a resistance-burning conductive material. Further investigations are in progress.

Acknowledgements. This work was financed by the Zhejiang Natural Science Foundation of China.

\section{REFERENCES}

1. T. Ito, H. Shirakawa, and S. Ikeda, J. Polym. Sci., Polym. Chem. Ed., 12, 11 (1974).

2. J. C. W. Chien, "Polyacetylene," Academic Press, New York, N.Y., 1984.

3. T. Masuda and T. Higashimura, Adv. Polym. Sci., 81, 121 (1987).

4. Z. H. Lu, T. H. Chen, and Y. S. Yang, Polym. Mater. 
Sci. Eng., 56, 690 (1987).

5. A. Furlani, M. V. Russo, P. Carusi, S. Licoccia, E. Leoni, and G. Valenti, Gazz. Chim. Ital., 113, 671 (1983).

6. M. G. Voronkov, V. B. Pukhnarevich, S. P. Sushchinskara, V. Z. Annenkova, and N. J. Andreeva, J. Polym. Sci., Polym. Chem. Ed., 18, 53
(1980).

7. M. J. Yang, M. Zheng, A. Furlani, and M. V. Russo, J. Polym. Sci., Polym. Chem. Ed., 32, 2709 (1994).

8. Z. Q. Shen, M. J. Yang, and M. X. Cai, Scientia Sinica, Series B, 26(8), 785 (1983).

9. M. J. Yang, J. Zhao, and Z. Q. Shen, J. Chinese Rare Earth Soc., 2(9), 5 (1987). 